\title{
Educación Superior pertinente y de calidad. Inclu- sión, diversidad, derechos humanos y extensión social: Experiencia de la Universidad Comunitaria Intercultural ${ }^{1}$
}

Higher Education with relevance and quality. Inclusion, diversity, human rights and social extension: An Experience of the Intercultural Community University

\author{
Alta Hooker Blandford2
}

\section{Resumen}

El presente ensayo discute y pone en perspectiva la contribución de la Universidad de las Regiones Autónomas de la Costa Caribe Nicaragüense (URACCAN), nacida en las entrañas de la Autonomía Regional, por sostener una Educación Superior intercultural, pertinente, de calidad, inclusiva y respetuosa de los derechos humanos de mujeres y hombres de los pueblos indígenas, afrodescendientes y étnicos en Abya Yala.

Justamente, en el artículo se reflexiona en la responsabilidad asumida por URACCAN por más de dos décadas, en promover y articular un nuevo paradigma descolonizador de la educación dirigido a asegurar el acceso a la Educación Superior de sectores históricamente invisibilizados y excluidos de la posibilidad de compartir, practicar y revitalizar sus tradiciones y costumbres, desde la colectividad.

Palabras Clave: Acompañamiento comunitario; Extensión universitaria comunidad.

\section{Abstract}

This essay discusses and puts in perspective the contribution of the University of the Autonomous Regions of the Nicaraguan Caribbean Coast (URACCAN) born in the bowels of the Regional Autonomy, for sustaining a higher intercultural, relevant, quality, inclusive and respectful education of the human rights of women and men of indigenous, Afro-descendant and ethnic peoples in Abya Yala.

Precisely, in the article there is a consideration on the responsibility assumed by URACCAN for more than two decades, to promote and articulate a new decolonizing paradigm of education aimed at ensuring access to Higher Education of sectors historically invisible and excluded from the possibility of sharing, practicing and revitalizing their traditions and customs, from the collectivity.

Key words: Community accompaniment; University extension, collectivity.

\footnotetext{
$\overline{1}$ XIV Congreso Latinoamericano y del Caribe de Extensión Universitaria y Segundo Congreso Centroamericano de Compromiso Social para la vinculación social de la universidad con la sociedad.

2 Master en Salud Pública. Rectora de la Universidad de las Regiones Autónomas de la Costa Caribe Nicaragüense. Correo: rectoria@uraccan.edu.ni. ORCID: http://orcid.org/0000-0003-1686-456X
} 


\section{Introducción}

Nicaragua presenta una realidad histórica con muchos desafíos, el $48 \%$ de su territorio nacional fue colonizado por los españoles en el siglo XVI. Esto significó para su población conquista, ocupación, pérdida de identidad, de organización social, de cosmovisión y explotación irracional de sus recursos naturales. Mientras, la Costa Caribe fue colonizada por los ingleses en el siglo XVII entrando así en contacto con sus habitantes, creando nexos económicos y políticos que vinieron a traducirse en el ejercicio de una colonización de dominio político y no cultural.

El caribe nicaragüense representa el 52\% del territorio nacional con veinte municipios donde conviven pueblos indígenas: miskitus, sumus mayangnas (ulwas, panamakas y tuaskas) y ramas; mestizos y afrodescendientes (creoles y garífunas). Cada uno de estos pueblos mantienen su lengua propia, cosmovisión, memorias colectivas, organización social, justicia consuetudinaria, espiritualidad, tierra y territorio que las diferencian entre sí y del resto de la población nacional, lo que demuestra claramente una gran diversidad sociocultural.

Cada cultura es portadora de una educación propia que le han permitido las enseñanzas y aprendizajes para atender sus necesidades de pervivencia, relacionamiento interno y externo, creando sus lenguajes y otras formas de comunicación para caminar la palabra, así como sus maneras de trabajar y establecer los tipos de formación que requiere cada pueblo.

Desde hace muchos años, los pueblos indígenas y afrodescendientes han venido luchando por modelos educativos que hagan visible su realidad y que responda a sus necesidades y expectativas. La Educación Superior ha sido parte de las demandas más sentidas de los pueblos de la Costa Caribe para incluir a los que siempre han estado excluidos. Para que los pueblos originarios puedan ejercer sus derechos a practicar

y revitalizar sus tradiciones y costumbres culturales, para que su historia y aportes se den a conocer. Este propósito ha impulsado a estos pueblos a ir uniendo el corazón y la razón en la construcción de instrumentos jurídicos internacionales, nacionales y regionales.

El reconocimiento de los pueblos ha significado un logro importante en materia de derechos. Estos derechos implican el acceso a la educación superior, que como bien sabemos nació como espacio de exclusión de la diversidad en la medida que sus fundamentos epistémicos, pedagógicos y culturales se fundamentan en la socialización de los valores monoculturales del eurocentrismo occidental, sin atender necesidades, demandas y propuestas de formación e investigación de y con los pueblos, aumentando así las brechas, las inequidades y las distintas formas de discriminación.

En este marco, nace la Universidad Comunitaria Intercultural URACCAN como hija legitima del régimen de Autonomía de la Costa Caribe de Nicaragua, conferido mediante la Ley 28, aprobada por la Asamblea Nacional en el año 1987 y puesta en funcionamiento en 1990, con la instalación de los primeros gobiernos autónomos, como resultado de las elecciones regionales en ese año. La Ley de Autonomía representa el modelo de organización político administrativo de la Costa Caribe y en ella se reconocen los derechos históricos ancestrales de los pueblos que en ella habitan.

\section{Desarrollo}

La Universidad de las Regiones Autónomas de la Costa Caribe Nicaragüense (URACCAN) es legítimamente constituida en el año 1992 y abre sus puertas en 1995 en el contexto de la necesidad de dar respuesta a la formación de talentos humanos para el fortalecimiento de la Autonomía Regional. Responde a una población multiétnica, multilingüe y pluricultural, que aporta al fortalecimiento de la identidad y revitalización de la cultura. 
Se fundamenta en la construcción de relaciones interculturales, el diálogo y práctica de las cosmovisiones y espiritualidades de los pueblos, la participación de las sabias, sabios, ancianas, ancianos, autoridades tradicionales y no tradicionales en la búsqueda y recreación de nuevos paradigmas y enfoques metodológicos en la generación de conocimientos para la construcción del buen vivir y las ciudadanías interculturales de género.

Desde sus raíces y su propio crecimiento, la URACCAN valora la diversidad humana y cultural como la principal riqueza, se inscribe en el marco del reconocimiento y ejercicio de derechos humanos y colectivos que los pueblos han reivindicado. Orienta sus esfuerzos hacia la construcción y reconstrucción de conocimientos apoyados en las prácticas y saberes endógenos, lucha contra la exclusión, la discriminación, el racismo institucionalizado y aporta al desarrollo con identidad de la región desde la cosmovisión de cada pueblo.

Una universidad que busca establecer mediante la creación, recreación de conocimientos y experiencia de los pueblos (investigación y la extensión) el vínculo entre las prácticas del aula y la realidad objetiva del entorno, a través de un proceso participativo, autogestionario y dinámico de los ciudadanos y ciudadanas interculturales que propicia su empoderamiento y a la vez que generen capacidades para transformar las realidades no favorables a las que pertenecen, haciendo mayor uso del diálogo de saberes y haceres como método de aprendizaje.

Está basada fundamentalmente en el principio de la interculturalidad que permite a docentes, investigadores y estudiantes, tener una relación horizontal con los comunitarios y comunitarias, haciendo de la práctica académica una interrelación, de confianza y esperanza entre los sujetos multiétnicos.

Este proceso ha implicado innumerables esfuerzos por hilar los conocimientos, saberes y elaborar día a día el tejido de una vida mejor, lo que ha dado relevantes resultados. Es así como podemos contar con cuatro recintos, cuatro extensiones, cinco institutos y dos centros de investigación, tres radios comunitarias y un canal de televisión local, ubicados físicamente en nueve municipios de la Costa Caribe que atienden, forman y capacitan a estudiantes indígenas, afrodescendientes y mestizos en diferentes comunidades, programas, niveles, modalidades y turnos a fin de empoderar, fortalecer la identidad y revitalizar la cultura, potenciando el proyecto social, político, económico y cultural de los diversos pueblos.

Nuestras dinámicas formativas se han caracterizado por partir de las expectativas, necesidades y potencialidades de los pueblos y comunidades, es así que poseemos programas académicos propios como: Medicina y Salud Intercultural, Sociología con mención en Autonomía, Educación Intercultural Bilingüe, Psicología en Contextos Multiculturales, Comunicación Intercultural, Maestría en Cosmovisiones del Buen Vivir y Vivir Bien, con énfasis en cambio climático, equidad y complementariedad y la escuela de liderazgo, así como el trabajo de los cinco institutos y dos centros de investigación. Donde se han identificado didácticas, metodologías, pedagogías y procedimientos que han facilitado los procesos de desarrollo de conocimientos, posicionando, difundiendo y caminando los saberes y prácticas de los pueblos en un nivel de universalidad.

Desde nuestra Universidad entendemos la función de Extensión como el acompañamiento comunitario, el cual es:

Un proceso de diálogo de saberes implementado por la universidad con las comunidades y actores sociales; encaminados al ordenamiento del desarrollo regional y fortalecimiento de los sistemas autonómicos y la promoción del patrimonio cultural desde un enfoque de equidad de género, para la construcción colectiva del Buen Vivir de los pueblos, el respeto, equilibrio y la armonía con la Madre Tierra a nivel nacional e internacional.

Teniendo en cuenta que la Comunidad es un espacio donde se desarrollan actividades sociales, políticas, culturales, ecológicas, lo que coincide con lo planteado por Carafa (1994), citado en Ledezma (2006): 
La Comunidad es un territorio común con cultivos familiares y colectivos; linderos defendidos conjuntamente y áreas de uso común para servicios, encuentros sociales, religiosos y festivos. Sus miembros cumplen obligatoriamente trabajos en forma conjunta, principalmente para construir y mantener los locales y servicios comunes. Cuentan con un sistema de autoridades propio, con poder de decisión sobre asuntos internos de interés comunal, como una serie de normas y principios éticos. Celebran de forma conjunta acontecimientos.

De esta manera, el acompañamiento comunitario está encaminado a propiciar aquellos procesos y acciones que realiza la Universidad en y con las comunidades y su liderazgo a fin de lograr el Desarrollo con Identidad/Buen Vivir.

Entendiendo el mismo como la percepción que tiene cada uno de los pueblos sobre la vida, sobre sus prácticas tradicionales, sus conceptos sobre salud-enfermedad, la revitalización cultural, la equidad de género desde la perspectiva y visión negra, indígena y no indígena y su participación en las decisiones que tienen que ver con sus vidas en colectividad, propiciando la felicidad, la vida en comunidad, hermandad y complementariedad en la búsqueda del bienestar desde su cosmovisión.

Hemos trabajado con 5 territorios indígenas miskitus, 5 territorios mayangnas, 1 territorio afrodescendiente creole, 1 territorio indígena rama y 21 comunidades mestizas constituidas en 5 centros de desarrollo.

Entre alguno de los logros como resultado de estos procesos podemos mencionar:

- Dos Observatorios, uno sobre violencia con cobertura nacional y el otro sobre Autonomía Regional, para aportar información oportuna a los principales tomadores de decisión en la región y para la elaboración de políticas públicas.

- Creación del Centro de Atención Psicosocial a la Mujer en Bluefields, como producto de la asignatura de proyectos innovadores en la carrera de psicología de estudiantes del Recinto Bluefields.

- Acompañamiento en la elaboración del plan de manejo de los Cayos Miskitus y la construcción del plan de vida al territorio Tawira.

- Acompañamiento en la elaboración de los estatutos y reglamento interno de la comunidad de Kamla.

- Reforestación en la Reserva de Yulu en coordinación con INAFOR, en el territorio Twi Waupusa.

- Realización de Pachamanca en la aplicación del diálogo de saberes y haceres como herramienta pedagógica para los procesos de revitalización, fortalecimiento de conocimientos, saberes y sabidurías comunitarias.

- Monitoreo de los principales indicadores ambientales del Saslaya y áreas protegidas.

- Elaboración de 12 libros de textos para séptimo, octavo y noveno grado en las materias de Español, Historia de la Costa Caribe, Geografía de la Costa Caribe, Gestión Cultural, Inglés y Educación Física; así como el desarrollo de programas y orientaciones metodológicas en cinco lenguas autóctonas (miskitu, tuahka, kriol, panamahka y ulwa).

- Se ha trabajo la revitalización de la cultura con las comunidades Ramas desde el nido de lenguas con niños de preescolar con ancianos de la comunidad. 
- En el caso del acompañamiento a la revitalización cultural garífuna, este ha consistido en procesos de intercambio entre Honduras y Nicaragua, en temas de enseñanza de la lengua, elaboración de instrumentos musicales, enseñanza de la danza y canto garífuna.

- Otro aspecto importante que estamos trabajando es la participación de las mujeres indígenas y negras en todos los procesos, cuidando que el enfoque de género sea coherente con sus propias prácticas y cosmovisiones, y no impere la visión occidental.

- En los currículos de las carreras se han establecido las prácticas de campo, desarrolladas por los y las estudiantes en las comunidades con la participación de líderes, sabios, sabias, médicos tradicionales quienes les orientan y participan de las reflexiones sobre los conocimientos tradicionales. De esta manera, se fortalecen los conocimientos adquiridos en las aulas de clase y entran en interacción con las prácticas productivas propias de las comunidades.

Por tanto, la pertinencia, calidad y sostenibilidad que planteamos como Universidad Comunitaria Intercultural, se fundamenta en la gestión articulada de programas, proyectos y acciones para perpetuar en el tiempo y espacio los alcances e impactos de los procesos, fundamentado en el consenso, participación, responsabilidad compartida, reciprocidad y complementariedad de cada uno de las y los actores, de cara al desarrollo con identidad y al fortalecimiento de las Autonomías de los pueblos.

\section{Conclusiones}

Podemos terminar afirmando basados en nuestra experiencia, que la Educación Superior en contextos multiculturales para que sea pertinente, de calidad y para que responda a las demandas y necesidades de toda la población debe fundamentarse en la construcción de relaciones interculturales, hacer visible la existencia de cada uno de sus pueblos desde las estadísticas, las historias, lenguas y culturas incluidas en los currículos, programas especiales de acceso, permanencia y graduación.

El abordaje del desarrollo debe hacerse desde las perspectivas de cada pueblo con enfoque intercultural de género y sus funciones deben estar articulados de manera estratégica que se logre combinar el conocimiento endógeno con el exógeno en la construcción del nuevo conocimiento. Debe haber nuevas metodologías que rompan con los paradigmas tradicionales de exclusión y que emerja el diálogo de saberes y haceres desde la comunitariedad para ir construyendo puentes de confianza y tener una Nicaragua unida en la diversidad.

\section{Lista de Referencias}

Ledezma, J. (2006). Género: Trabajo agrícola y tierra. Cochabamba. Bolivia: Ediciones Abya Yala.

URACCAN (2014). Plan Estratégico participativo de la URACCAN (PEI, 2015-2019). Construyendo el camino de la Educación Intercultural Comunitaria con calidad. Managua, URACCAN.

URACCAN (2015). URACCAN: Universidad Comunitaria Intercultural: Perfil institucional. Managua, URACCAN. 